Jurnal Artikel

\title{
Pengaruh Termal Dan Jarak Arc Spray Terhadap Sifat Mekanik Baja Karbon ( AISI 1045 )
}

\author{
Andi Saidah $^{1^{*}}$, Asrol Basri ${ }^{2}$ \\ 1,2 Jurusan Teknik Mesin Universitas 17 Agustus 1945 Jakarta \\ 1 andisaidah@yahoo.co.id \\ *Corresponding author - Email : andisaidah@yahoo.co.id
}

Artkel Info - : Received : 4 Aug 2020; Revised : 30 Aug 2020; Accepted: 31 Aug 2020

Penggunaan logam dalam perkembangan teknologi dan industri sebagai salah satu material penunjang yang sangat besar perannya, akan tetapi di lapangan banyak faktor yang menyebabkan daya guna logam menurun, diantanya berupa adanya laju keausan yang tinggi dan umur pendek karena sering mengalami kegagalan yang dimulai dari permukaan atau bidang kontak. Untuk mengatasi hal tersebut dilakukan cara alternatif yaitu dengan pelapisan menggunakan metode thermal arc spray AESP (Electric Arc Spraying). melakukan pelapisan logam dengan material yang memiliki ketahanan aus yang lebih baik. Pada penelitian ini menggunakan material coating $60 \mathrm{~T} 13 \%$ crhome steel pada material substrat baja karbon rendah (AISI 1045) dengan variasi jarak spray (80mm, 100A) (220mm, 120A) dan (320mm, 150A) dengan metode thermal arc spray. Hasil pengujian macro secara visual spesimen tidak di temukan cacat pelekatan material coating dan berfungsi dengan baik. Hasil pengujian dengan menggunakan roughness tester nilai kekasaran tertinggi yaitu 0,34 $\mu \mathrm{m}$. Hasil uji kekerasan dengan metode hardness test di peroleh nilai kekerasan permukaan tertinggi yaitu 429,56 HB. Pengujian kekuatan tarik menunjukkan semakin jauh jarak spray yang digunakan maka hasil nilai kekuatan tarik semakin tinggi. Di mana hasil nilai kekuatan tarik tertinggi yaitu $428 \mathrm{MPa}$

Kata kunci: Baja Karbon rendah AISI 1045 ,Thermal Arc Spray, Variasi Jarak semprotan

\section{Abstract}

The use of metals in technological and industrial developments as one of the supporting materials has a very large role, but in the field there are many factors that cause metal's usefulness to decrease, including the high wear rate and short life due to frequent failures starting from the surface or plane. contact. To overcome this, an alternative method is used, namely by coating using the AESP (Electric Arc Spraying) thermal arc spray method. perform metal plating with materials that have better wear resistance. In this study, using a coating material of $60713 \%$ crhome steel on a low carbon steel substrate (AISI 1045) with a variety of spray distances $(80 \mathrm{~mm}, 100 \mathrm{~A})(220 \mathrm{~mm}, 120 \mathrm{~A})$ and $(320 \mathrm{~mm}, 150 \mathrm{~A})$ with the thermal arc spray method. The results of the macro test visually specimens found no adhesion defects of the coating material and it is functioning properly. The test results using a roughness tester, the highest roughness value is $0.34 \mu \mathrm{m}$. The hardness test results using the hardness test method obtained the highest surface hardness value, namely $429.56 \mathrm{HB}$. The tensile strength test shows that the farther the spray distance is used, the higher the tensile strength value. Where the result of the highest tensile strength value is $428 \mathrm{MPa}$

Keywords: Carbon Steel AISI 1045, Thermal Arc Spray, Spray Distance Variation

\section{BELAKANG MASALAH}

Dalam mengatasi masalah keausan pada logam salah satunya adalah mengganti komponen mesin tersebut atau dengan cara melapiskan material pada komponen mesin yang mengalami keausan untuk mengembalikan ke ukuran semula. Metode yang sering digunakan 
adalah thermal arc spray, yaitu suatu proses pelapisan di mana bahan bakunya dipanaskan, kemudian diteteskan ke permukaan. Dalam thermal arc spray, material dapat berupa serbuk, kawat atau batang, dan di masukan ke dalam flame yang dihasilkan oleh spray gun, di mana material akan meleleh dan disemprot secara cepat menuju substrat yang akan dilapisi.

Proses thermal arc spray secara luas digunakan karena memiliki biaya yang relatif rendah dan terjadinya kualitas pelapisan yang buruk dapat dicegah, dalam aplikasinya proses ini digunakan dalam hal proteksi korosi pada struktur dan komponen. Tidak terbatas pada material logam saja, dan juga pada material non logam.

Pelapisan dengan metode thermal arc spray digunakan untuk meningkatkan ketahanan korosi dan ketahanan aus, perlindungan terhadap elektromagnetik atau elektrostatik, perlindungan terhadap gangguan frekuensi radio, metal buildup, dan kosmetik. Dalam proses thermal arc spray setiap pengerjaannya selalu menginginkan suatu hasil pelapisan yang baik.

Dalam proses pelapisan kemungkinan terjadinya kesalahan yang tidak dapat dihindarkan dan akan berakibat fatal pada sifat mekaniknya. Terjadinya kesalahan proses pelapisan tersebut dapat terjadi akibat dari kesalahan teknis dan non teknis.

\section{TINJAUAN PUSTAKA}

\subsection{Baja karbon rendah ( AISI 1045 )}

Bahan AISI 1045 adalah baja karbon yang mempunyai kandungan karbon sekitar (0.43 $0.50 \% \mathrm{C}$ berat) termasuk golongan baja karbon rendah (Nugroho, 2005). Baja AISI 1045 merupakan baja karbon karena sesuai dengan pengkodean internasional, yaitu 10xx berdasarkan nomen klatur yang dikeluarkan oleh AISI dan SAE ( society of aoutomotive engineers ) pada angka 10 pertama merupakan kode yang menunjukkan plain carbon dan kode xxx sesudah angka 10 menunjukkan komposisi karbon. Sehingga baja AISI 1045 merupakan baja karbon atau plain carbon steel yang memiliki komposisi karbon sebesar $0.45 \%$. baja karbon AISI 1045 banyak digunakan di komponen - komponen mesin seperti roda gigi, poros dan bantalan. Pada penggunaannya baja AISI 1045 harus memiliki sifat ketahanan aus yang baik, karena akan mengalami gesekan antara komponen - komponen lainnya yang mengakibatkan keausan.

Tabel 2.1. Komposisi Kimia Baja AISI 1045 (PT. Bhinneka Bajanas, 2019)

\begin{tabular}{ccccccc}
\hline kode & $\mathrm{C} \%$ & $\begin{array}{c}\mathrm{Si} \\
\%\end{array}$ & $\begin{array}{c}\mathrm{Mn} \\
\%\end{array}$ & $\begin{array}{c}\text { Mo } \\
\%\end{array}$ & $\mathrm{P} \%$ & $\mathrm{~S} \%$ \\
\hline AISI & 0.46 & 0.19 & 0.65 & 0.025 & 0.18 & 0.14 \\
1045 & & & & & & \\
\hline
\end{tabular}

Tabel 2.2. Sifat mekanis Baja Karbon AISI 1045 (https:www//azom.com, 2013)

\begin{tabular}{lll}
\hline \multicolumn{1}{c}{ Sifat Mekanik } & \multicolumn{2}{c}{ Keterangan } \\
\hline Kekuatan tarik & $585 \mathrm{MPa}$ & $84800 \mathrm{psi}$ \\
Batas ulur & $450 \mathrm{Mpa}$ & $65300 \mathrm{psi}$ \\
Modulus geser & $80 \mathrm{GPa}$ & $11600 \mathrm{ksi}$ \\
Modulus elastisitas & $200 \mathrm{GPa}$ & $29000 \mathrm{ksi}$ \\
Posisi ratio & 0,29 & 0,29 \\
Perpanjangan putus & $12 \%$ & $12 \%$ \\
(in 50mm) & & \\
Hardness brinell & 163 & 163 \\
Hardness knoop & 184 & 184 \\
Hardness rockwell & 84 & 84 \\
Hardness vickres & 170 & 170 \\
Massa jenis & $7,87 \mathrm{~kg} / \mathrm{cm}^{3}$ & $0,284 \mathrm{lb} / \mathrm{in}^{3}$ \\
Surface Roughness & $0,31 \mu \mathrm{m}$ & $0,31 \mu \mathrm{m}$ \\
\hline
\end{tabular}

\subsection{Pelapisan (coating)}

Pelapisan (coating) adalah suatu proses penambahan atau penumpukan material ke material lainnya. Di harapkan dapat memberikan sifat tertentu pada permukaan material yang dilapisi dalam bentuk perbaikan struktur mikro maupun ketahanannya, dan perbaikan terhadap sifat fisiknya. Pada umumnya proses pelapisan digunakan untuk melapisi permukaan material dengan tujuan:

1. Melindungi permukaan material yang dilapisi dan lingkungan yang mungkin menyebabkan korosi.

2. Sifat mekanik material harus dapat memenuhi kondisi komponen yang bersangkutan.

3. Untuk memperbaiki permukaan material atau bentuk komponen yang rusak.

Pelapisan berfungsi untuk melindungi material yang dilapisi dari serangan korosi. Dalam proses pelapisan material coating yang ideal harus memiliki faktor sebagai berikut :

1. material pelapis harus lebih tahan dari material yang di lindungi.

2. material pelapis tidak boleh menimbulkan korosi setelah melapisi material yang dilindungi.

3. Sifat mekanik dan fisik seperti kekuatan, ketahanan abrasi, ketahanan korosi,dan sifat termal harus memenuhi kondisi operasi komponen yang bersangkutan. 
4. Metode pelapisan harus sesuai dengan metode pabrikasi komponen.

5. Tebal lapisan harus homogen dan tidak mengandung pori.

Pelapisan terdiri dari beberapa metode pelapisan dan pemilihan metode pelapisan didasarkan pada bentuk,ukuran, dan kemampuan adaptasi material terhadap metode yang digunakan,tingkat adhesi dan ketersediaan alat.

Coating deposition dibagi menjadi tiga kategori. Ada tiga teknik dalam hard facing yaitu cladding, welding, dan thermal spraying. Coating harus dapat memberikan penghalang secara terus menerus pada substrat, sebab ke tidak kesempurnaan lapisan bisa menyebabkan degradasi dan korosi pada substrat. Tingkat proteksi dari pelapisan tergantung pada sistem keseluruhan dari pelapisan yang terdiri dari jenis pelapisan, substrat logam dan preparasi permukaan.

\subsection{Thermal arc spray}

Thermal spray merupakan teknik rekayasa permukaan menunjukkan skema prinsip dasar thermal spray yaitu dengan mendepositkan partikular dalam bentuk cair atau padat ke substrat di mana material pelapis dipanaskan dan didorong sebagai partikel induvidu atau droplets ke suatu permukaan material substrat (Pawlowski, 2008). Thermally sprayed coatings memberikan permukaan material yang berfungsi untuk melindungi atau memodifikasi perilaku substrat yang ingin diberikan proteksi (Dorfarman, 2005). Energi thermal yang digunakan untuk melelehkan material pelapis dapat dibagi menjadi dua kategori, yaitu electrical dan flame heating. Saat material dipanasi, material berubah menjadi keadaan plastis atau meleleh di kurang serta diberi kecepatan oleh oksigen menabrak substrat dan membentuk lapisan tipis (splats) menyesuaikan dan menempel pada permukaan substrat yang tidak rata dengan partikel pelapis yang lain.

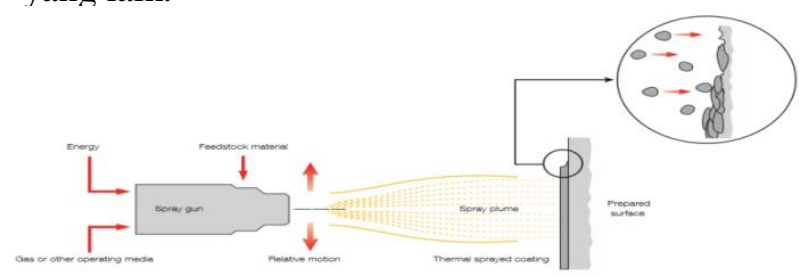

Gambar 2.1 Prinsip dasar thermal arc spray (Oerlicon, 2016)
Setelah dingin akan terbentuk lapisan yang tidak homogen dan umumnya terdapat derajat porositas dan oksida logam. Material feed stock dapat berupa apa saja yang dapat dilelehkan termasuk logam, senyawa logam, cerment oksida,gelas, dan polimer, dapat juga dalam bentuk powder, wire atau rod. Pengikat antara substrat dan pelapis dapat berupa ikatan mekanik, kimia, metalurgi atau kombinasi ketiganya. Sifat-sifat dari pelapis bergantung pada jenis material proses thermal spray dan parameter-parameter yang diterapkan dan perlakuan setelah proses thermal spray pada pelapis. Thermal spray mengurangi ketahanan abrasi dan korosi sehingga memperpanjang umur perawatan dari sebuah part dengan menggunakan material coating dengan performa tinggi di atas material substrat tingkat rendah. Lebih dari 200 material coating dengan perbedaan karakteristik ketangguhan, koefisien gesek, kekerasan, dan berbagai karakteristik lainnya. Material coating dapat diklasifikasikan seperti pure metals, metal alloys, cermets (Ceramic metals), ceramics, carbide, polymers, special composite materials. Secara umum thermal spray dibedakan menjadi lima metode, yaitu:

- Oxyfuel wire (OFW) spray

- Electric arc wire (EAW) spray

- Oxyfuel powder (OFP) spray

- Plasma arc (PA) powder spray

- High-velocity oxyfuel (HVOF) powder spray Pada setiap metode memiliki karakteristik yang berbeda. Energi thermal pada setiap metode ditentukan oleh temperatur operasi yang dapat dicapai dan energi kinetik dari partikel semprot di tentukan dari kecepatan gas (Oerlicon, 2016).

\section{METODOLOGI PENELITIAN}

\subsection{Langkah Penelitian}

Langkah penelitian yang dilakukan adalah sebagai berikut :

a) menyiapkan peralatan, mesin thermal arc spray, bahan atau material coating dan menggunakan perlengkapan keselamatan kerja.

b) Mulai proses pelapisan pada substrat yang akan dilapisi menggunakan mesin thermal arc spray.

c) Pembuatan spesimen yang akan di uji menggunakan mesin bubut.

d) Melakukan pengulangan proses pelapisan dengan variasi jarak spray yang telah di 
tentukan yaitu $\mathrm{A}(80 \mathrm{~mm}, 100 \mathrm{~A}),(220 \mathrm{~A}$, 120A) dan C(320A, 150A).

e) Melakukan proses finishing spesimen yang telah dilapisi menggunakan mesin bubut.

\subsection{Waktu dan Tempat}

Proses thermal arc spray AESP (Electric arc spraying) lapisan 60T 13\% crohme steel pada baja karbon rendah (AISI 1045) dengan variasi jarak spray. Dilakukan di workshop PT. $\mathrm{x}$ dan untuk proses pengujian sifat mekanik dilakukan di BKI (Balai Klarifikasi Indonesia) selama kurang lebih 3 bulan.

\subsection{Alat dan Bahan Penelitian}

\subsubsection{Material substrat}

Pada penelitian ini material baja karbon rendah (AISI 1045) digunakan sebagai substrat yang akan di lapisi. Material ini sesuai dalam aplikasi penggunaannya untuk pemakaian yang bersangkutan dengan gesekan, seperti berikut : roda gigi,shaft, bantalan dan komponen-komponen mesin lainnya.

\subsubsection{Material Lapisan 60T 13\% chrome steel}

Sebagai material pelapis yang digunakan untuk pelapisan pada substrat. Material ini memiliki ketahanan aus yang sangat baik dan ketahanan korosi yang sangat baik. Dimana 60T sebagai kode stainless steel dan kandungan $13 \%$ chrome steel. Pada umumnya banyak digunakan untuk perbaikan elemenelemen mesin dan dimensi restorasi.

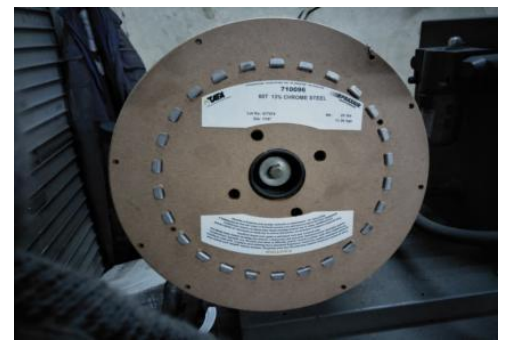

Gambar 3.1. Material wire 60T 13\% chrome steel

\subsubsection{Brwon Alumunium oxide (Al2O3)}

Penelitian ini menggunakan aluminium oxide 24 mesh digunakan sebagai abrasive gret blasting permukaan yang akan di coating, agar ikatan mekanik antara coating dengan substrat lebih baik dan menghilangkan kotoran pada permukaan substrat.
3.4.Proses pembuatan spesimen baja karbon rendah (AISI 1045)

- Melakukan proses pemotongan sampel baja karbon rendah (AISI 1045) dengan ukuran diameter $30 \mathrm{~mm}$, panjang $300 \mathrm{~mm}$ sebanyak 6 pcs dan diameter $25 \mathrm{~mm}$, panjang 30mm sebanyak 3 pcs.

- Selanjutnya pembuatan spesimen menggunakan mesin bubut.

- Setelah pembubutan kemudian pemukaan substrat yang akan di coating di panaskan menggunakan las blender dengan suhu $30^{\circ} \mathrm{C}-50^{\circ} \mathrm{C}$. Untuk menghilangkan minyak yang terkandung pada substrat.

- Kemudian proses sandblasting pada permukaan substrat untuk membersihkan permukaan substrat dan memberikan profil agar permukaan substrat dapat dilapisi dengan baik.

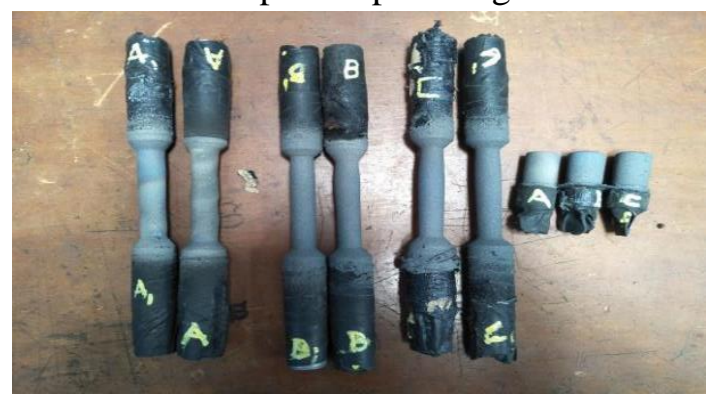

Gambar 3.2. Hasil spesimen yang telah di coating

\section{HASIL DAN PEMBAHASAN}

\subsection{Hasil uji macro}

Pengujian macro pada permukaan substrat baja karbon rendah (AISI 1045) dengan menggunakan metode thermal arc spray dengan material pelapis 60T 13\% chrome steel. Pengujian macro dilakukan di PT. Biro Klasifikasi Indonesia. Proses pelapisan di lakukan dengan variasi jarak dan ampere $\mathrm{A}(80 \mathrm{~mm} \mathrm{100A),} \mathrm{B(220mm} \mathrm{120A),} \mathrm{C(320mm}$ 150A). Hasil pengujian dapat dilihat pada gambar dibawah ini.

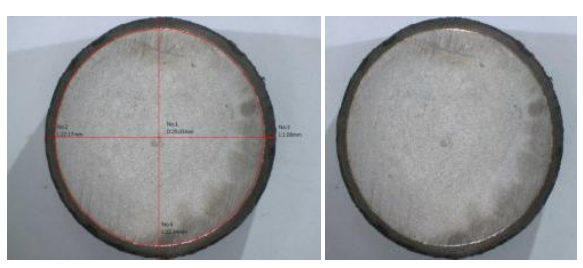




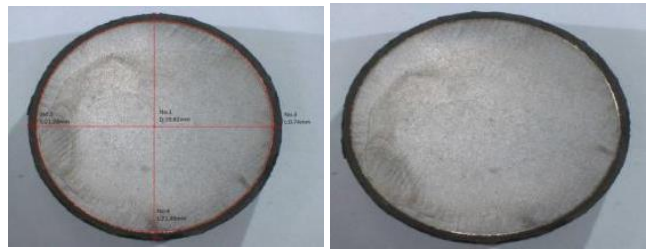

Gambar 4.1. Hasil uji sampel (A),B,dan C visual macro

Dapat dilihat pada gambar 4.1. hasil pengujian macro secara visual pada sampel A,B,C, dengan jarak spray $80 \mathrm{~mm}$ dan ampere 100A. Menunjukkan perekatan, peleburan dan penembusan lapisan material coating berfungsi dengan baik tidak ada cacat rongga atau lobang antara material substrat dan material lapisan.

\subsection{Hasil Pengujian Kekasaran dengan Metode Roughness Tester}

Pengujian kekasaran dilakukan pada permukaan baja karbon rendah (AISI 1045) yang dilapisi material coating 60T $13 \%$ chroom steel menggunakan metode thermal arc spray. bertujuan untuk mengetahui nilai kekasaran dan morfologi permukaan yang telah di lapisi. Proses pengujian dilakukan di PT. Goltens Indonesia, alat yang digunakan roughness tester tipe sutronic S116. Nilai kekasaran dinyatakan dalam roughness average ( $\mathrm{Ra})$. $\mathrm{Ra}$ merupakan parameter kekasaran yang paling banyak dipakai secara internasional dan didefinisikan sebagai rata rata aritmetika dan penyimpangan mutlak profil kekasaran dari garis tengah rata-rata.

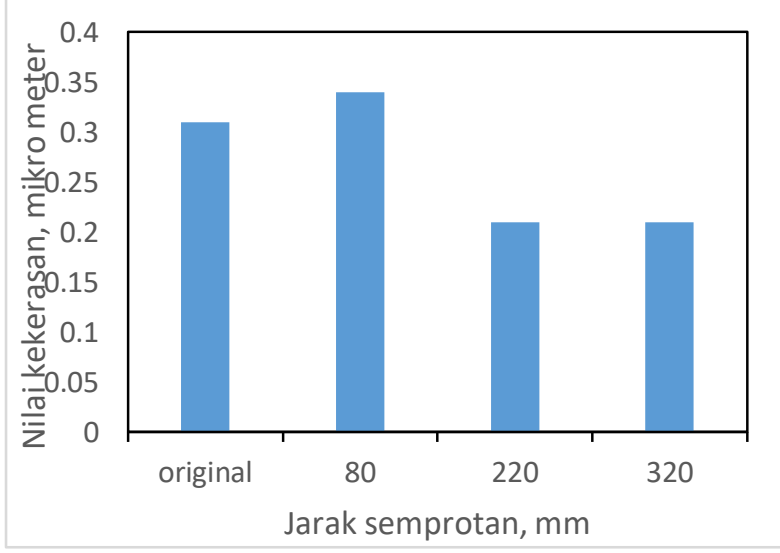

Gambar 4.2. Grafik hubungan antara nilai kekasaran dengan jarak semprotan

Gambar 4. merupakan nilai hasil rata-rata kekasaran permukaan spesimen yang di coating dengan variasi jarak spray. Dapat dilihat pada gambar 4.2. bahwa sampel A jarak spray $(80 \mathrm{~mm})$ mempunyai nilai kekerasan yang paling tinggi yaitu $0,34 \mu \mathrm{m}$ tidak terlalu jauh dengan nilai kekasaran original yaitu $0,31 \mu \mathrm{m}$ dan menurun pada sampel B jarak spray (220mm) yang mempunyai nilai kekerasan 0,21 $\mu \mathrm{m}$ kemudian sampel $\mathrm{C}$ jarak spray (320mm) memiliki nilai kekasaran yang sama pada sampel B yaitu sebesar $0,21 \mu \mathrm{m}$. Sampel B dan sampel C memiliki porosity yang lebih rendah dan permukaan yang lebih halus dibandingkan dengan sampel A memiliki porosity yang tinggi dan permukaan lebih kasar. Menurut penelitian sebelumnya nilai kekasaran yang tinggi diakibatkan jarak spray yang terlalu dekat sehingga partikel lapisan belum melting secara sempurna saat mengenai permukaan substrat sehingga menimbulkan splat partikel bulat berukuran besar pada proses solidifikasi, dibandingkan dengan jarak spray yang lebih jauh nilai kekasarannya lebih kecil karena partikel mempunyai waktu lebih lama untuk melting sehingga splat yang terbentuk lebih kecil dan halus. Bentuk bulat partikel yang di hasilkan akan menyebabkan rongga pada permukaan coating sehingga nilai porosity dan kekasarannya akan lebih besar (Kurniawati, 2017), disamping itu bahwa semakin dekat jarak nozzle spray yang digunakan maka semakin naik tingkat kekerasan specimen yang diperoleh, hal ini terjadi karena jarak nozzle spray yang semakin dekat mengasilkan droplet yang mencapai permukaan substrat lebih tebal sehingga akan menaikan kerapatan permukaan dan porositas coating, sehingga tingkat kekerasannya juga meningkat.

\subsection{Hasil Pengujian Kekerasan dengan Metode Hardness Brinell}

Pengujian kekerasan pada spesimen baja karbon rendah (AISI 1045) yang dilapisi material coating 60T $13 \%$ crhome steel. Pengujian menggunakan metode hardness brinell untuk mengetahui nilai kekerasan dalam bentuk daya tahan material terhadap bola baja (identor) yang ditekankan pada material spesimen. Tipe alat yang di gunakan equotip 3 S/N E301-006-1977, hasil nilai kekerasan dapat dilihat pada grafik sebagai berikut : 


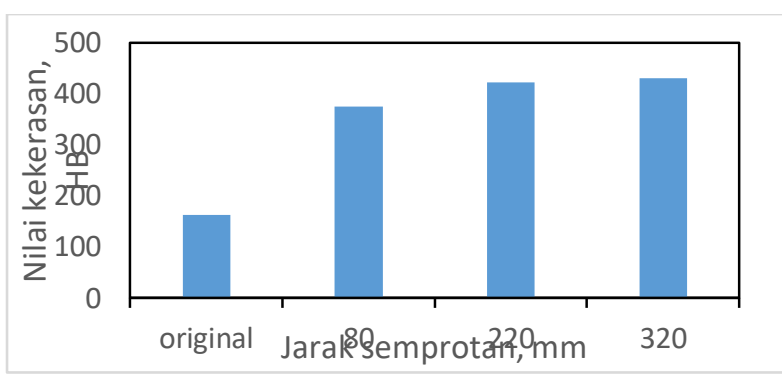

Gambar 4.3. Grafik nilai kekasaran menggunakan metode hardness brinell

Dari grafik 4.3. di atas menunjukkan peningkatan nilai kekerasan permukaan spesimen dari nilai terendah kekerasan original $163 \mathrm{HB}$ nilai kekerasan meningkat terus $374,55 \mathrm{HB}$ dengan jarak spray $80 \mathrm{~mm}$ dan $421,12 \mathrm{HB}$ jarak spray $220 \mathrm{~mm}$ meningkat mencapai titik nilai kekerasan permukaan tertinggi yaitu $429,56 \mathrm{HB}$ dengan jarak spray $320 \mathrm{~mm}$. Hal tersebut terjadi dikarenakan dengan jarak yang dekat menyebabkan partikel coating belum malting secara sempurna pada saat mengenai substrat sehingga mengakibatkan splat berukuran besar pada proses solidifikasi, sehingga menghasilkan kerenggangan antara partikel dan nilai kekasaran menjadi rendah sedangkan dengan jarak spray yang lebih jauh memiliki waktu yang lebih lama untuk melting sehingga splat yang terbentuk lebih kecil menghasilkan kerapatan dan kekerasannya lebih tinggi (Kurniawati, 2017). Hal ini sesuai dengan penelitian sebelumnya menunjukkan bawah jarak spray merupakan parameter penting yang berpengaruh signifikan terhadap kekerasan, porositas dan kekasaran coating.

\subsection{Hasil Pengujian Tarik}

Pengujian tarik pada spesimen baja karbon rendah (AISI 1045) yang dilapisi material coating 60T $13 \%$ crohme steel dengan menggunakan metode thermal arc spray dan tipe mesin uji tarik yang digunakan TENSILON RTF 2410 sekala beban 10 ton. Pengujian dilakukan di PT. BIRO KASIFIKASI INDONESIA, pada tanggal 25 april 2019. Pengujian ini bertujuan untuk mengetahui sifat-sifat mekanis dari spesimen yang telah di coating, sifat mekanis tersebut antara lain meliputi batas lumer,kekuatan tarik,kekenyalan,pertambahan panjang dan pengecil luas penampang.

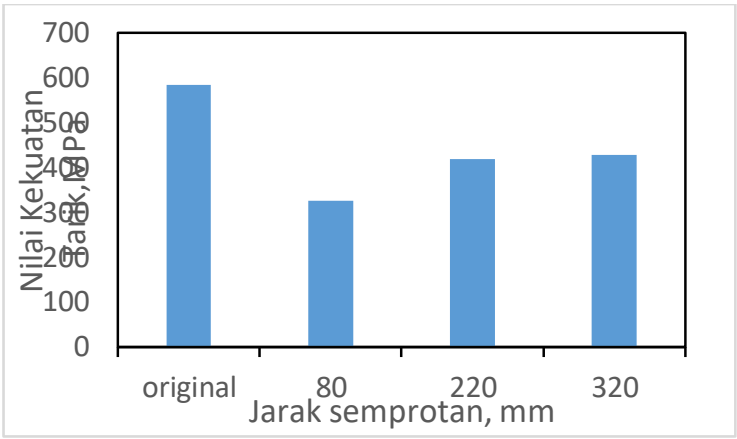

Gambar 4.4 Grafik nilai kekuatan tarik spesimen

Gambar 4.4. menunjukkan hasil grafik secara perbedaan signifikan dari nilai kekuatan tarik original yaitu $585 \mathrm{MPa}$ kekuatan tarik sampel A mempunyai nilai terendah yaitu $326 \mathrm{MPa}$ dengan jarak spray $80 \mathrm{~mm}$, sedangkan sampel B mempunyai nilai kekuatan tarik yaitu 417 MPa dengan jarak spray $220 \mathrm{~mm}$, dan terus meningkat pada sampel $\mathrm{C}$ mempunyai nilai kekuatan tarik tertinggi yaitu $428 \mathrm{MPa}$ jarak spray $320 \mathrm{~mm}$. Menurut penelitian (Santoso $\mathrm{dkk}$,2015) menunjukkan variasi ampere (kuat arus listrik thermal arc spray) mempengaruhi kekuatan tarik material lapisan semakin dekat jarak spray dari materialnya, menyebabkan partikel coating belum malting secara sempurna pada saat mengenai substrat sehingga mengakibatkan splat berukuran besar pada proses solidifikasi, sehingga menghasilkan kerenggangan antara partikel dan nilai kekuatan tariknya menjadi kecil, sebaliknya dengan jarak spray yang menjadi rendah sedangkan dengan jarak spray yang lebih jauh memiliki waktu yang lebih lama untuk melting sehingga splat yang terbentuk lebih kecil menghasilkan kerapatan dan nilai kekuatan tariknya lebih tinggi (Kurniawati, 2017).

\section{A. KESIMPULAN}

Berdasarkan hasil data yang diperoleh dari pengujian yang dilakukan dapat disimpulkan sebagai berikut :

- Berdasarkan hasil pengujian macro pada sampel A dengan jarak spray $80 \mathrm{~mm}$, sampel B dengan jarak spray $220 \mathrm{~mm}$, dan sampel $\mathrm{C}$ dengan jarak spray $320 \mathrm{~mm}$, menunjukkan hasil pengujian yang tidak mengalami cacat diantaranya retak, rongga, atau berlubang pada spesimen. Peleburan, penembusan dan pelekatan coating berfungsi dengan baik yang dilihat secara visual dengan 
menggunakan alat microscope $\mathrm{KH}-$ 1300 .

- Nilai kekasaran tertinggi yang menggunakan metode roughness tester pada sampel A dengan jarak spray 80mm, menunjukkan nilai kekasaran tertinggi yaitu $0,34 \mu \mathrm{m}$ dan terendah sebesar $0,21 \mu \mathrm{mm}$

- Peningkatan jarak spray dengan metode hardness tester menghasilkan nilai kekerasan tertinggi $429 \mathrm{HB}$ dengan jarak spray $320 \mathrm{~mm}$, dan terendah sebesar $374,55 \mathrm{HB}$ pada jarak spray $80 \mathrm{~mm}$.

- Peningkatan jarak spray sangat mempengaruhi nilai kekuatan tarik. Berdasarkan hasil pengujian nilai kekuatan tarik tertinggi pada jarak spray $(320 \mathrm{~mm}, 150 \mathrm{~A})$ yaitu $428 \mathrm{MPa}$ tetapi memiliki perbedaan yang sangat signifikan dengan material original yaitu $585 \mathrm{MPa}$.

\section{DAFTAR PUSTAKA}

Dorfman, M.R. (2005). "Thermal Spray Coating in Handbook of Environmental Degradation of Materials". Norwich: William Andrew Publishing.

Gunardhi, Risky Nur Dede, 2018 “Analisa Sifat Mekanik dan Struktur Micro Besi Cor Fc-25 Setelah Melalui Proses Heat Traetmen", Jurnal jurusan teknik mesin fakultas teknik. Univeristas Pamulang.

Harianto, Andhi, 2007. "Setudi karakterisasi material poros bantalan yang di rekondisi dengan proses penambahan baja chrome 13\% dengan metode thermal spray", Jurnal Jurusan Teknik Mesin Fakultas Teknik Industri. Universitas Mercu Buana.

Kurniawati Fajar, 2017. "Pengaruh variasi jarak spray lapisan FeCrMnNiCSi metode wire arc spray terhadap abrasive wear resistence dan porositas gres cast airon fc25", Jurnal Jurusan Teknik Material dan Metalurgi Fakultas Teknologi
Industri. Institut Teknologi Sepuluh November.

Putra,Sukma Ade Fransiscus, 2012. "Pengaruh arus dan waktu pelapisan hard chrome terhadap

ketebalan lapisan dan kekerasan pada plat baja karbon rendah AISI 1026 dengan elktroplating menggunakan $\mathrm{HCrO} 3250 \mathrm{gr} / \mathrm{lt}$ dan H2SO4 1,25 gr/lt”, Jurnal Jurusan Teknik Mesin Fakultas Teknik.

Universitas Sebelas Maret Surakarta.

Putra, Tantyo Rifqi, 2017. "Pengaruh tekanan gas pada metode thermal arc spray terhadap sifat mekanik dan merfology pelapisan FeCrMnNiCSi pada Grey cast iron FC 25". Jurnal jurusan Teknik Material dan Metalurgi, Universitas Insitut Teknologi Surabaya.

Pawlowski, Lech . 2008. "The Science and Engineering of Thermal Spray Coating Second Edition". The Atrium,Southern Gate, Chichester,West Sussex PO19 8SQ, England: John Wiley \& Sons Ltd.

Purwaningsih, Hariyati dkk. 2010. "Studi Antar Muka Top Coat dan Bond Coat pada Rekayasa pelapisan Alumina Sebagai Lapisan Perintang Panas untuk Aplikasi Temperatur Tinggi".Jurnal jurusan Teknik Material dan Metalurgi, Insitut Teknologi Surabaya.

Stachowiak, G. W., Batchelor, A.W., (2005). "Engineering Tribology," Elsevier, 3rd ed., Burlington.

Sugiono, Setyawan dan Setiyorini, yuli 2013. "Pengaruh variasi sudut nozzle dan jaraknozzle pada arc spray coating terhadap ketahanan abrasife lapisan $13 \%$ chrome steel", Jurnal Jurusan Teknik Material dan Metalurgi Fakultas Teknologi Industri. Insitut Teknologi Sepuluh November. 
Susilowati, S. E. (2017). Studi Perlakuan Alkali terhadap Sifat Mekanik Bahan Komposit Berpenguat Sekam Padi. Jurnal Kajian Teknik Mesin, 2(1), 67-80. 